\title{
Group clinical supervision for nurses: process, group cohesion and facilitator effect
}

\author{
AUTHORS \\ DEBBIE J RESCHKE BEc GDipDevAdmin MPopSt ${ }^{1}$ \\ CHRIS DAWBER Ma MH Nursing, $\mathrm{Ma} \mathrm{MH}$ \\ Psychotherapy, Cert Dev Psych, MHN Cred ${ }^{2}$ \\ PRUDENCE M MILLEAR PhD, Ba Psychology \\ (Honours) $^{1}$ \\ LUIGI MEDORO DClinPsych, PostGrad Dip Psych, BA ${ }^{2}$ \\ 1 School of Health and Behavioural Sciences, University of \\ the Sunshine Coast, Queensland, Australia \\ 2 Mental Health and Addiction Service, Sunshine Coast \\ University Hospital \& Health Service, Queensland, Australia

\section{CORRESPONDING AUTHOR} \\ CHRIS DAWBER Sunshine Coast University Hospital \& Health Service PO Box 367, Golden Beach, QLD, \\ Australia 4551. Email: Chris.Dawber@health.qld.gov.au
}

\section{ABSTRACT}

Objective: This qualitative research project set out to explore how, and by what means, participation in group clinical supervision might impact nurses. It aimed to describe participant perceptions of the processes within a long running reflective practice group for intensive care nurses and explore these in relation to relevant theory.

Background: Interpersonal aspects of care are central to the nursing role, however, the associated emotional labour can develop into moral distress, compassion fatigue and burnout. Australia's peak nursing and midwifery bodies have released a joint position statement on the importance of supervision for nurses. Group supervision interventions, such as reflective practice groups, mitigate stress, promote learning and support interpersonal aspects of nursing.

Method: Twenty-two intensive care nurses from a reflective practice group that had been running for 10 years, participated in focus groups convened by an independent researcher. Thematic analysis identified key perceptions relating to process and outcomes.
Results: Group identification, voluntary participation and skilled facilitation created an enabling environment for nurses to self-disclose. The sense of universality experienced by participants, along with increased empathy, enabled reflection and selfevaluation relevant to the group prototype of the ideal nurse. Authentic emotional expression was seen to provide respite from emotional labour, thereby regenerating resources for nurses to cope with job demands.

Discussion: Key themes can be aligned to social psychology constructs of group identity, task interdependence and homogeneity, supporting earlier studies that suggest group cohesion is comprised of measurable factors. By developing and aligning with these constructs, the facilitator assists the group to establish a safe space whilst conceptualising and aspiring to a model for the professional and compassionate nurse.

Conclusion: Social psychology constructs can help develop practice and research of group supervision for nurses. In clinical nursing settings, group identity is particularly salient and facilitator interventions should aim to strengthen this. The development of a 
sense of universality, when combined with voluntary participation and a focus on intra-group process, can enhance cohesion and create a safe space for selfdisclosure. This enables nurses to explore actions and responses to clinical situations and explore emotions incongruent with the ideal nurse prototype, thereby promoting restorative and formative benefits.

Implications for research, policy, and practice: This study adds to our understanding of processes in group clinical supervision for nurses and suggests that it is appropriate to apply social identity theory to improve practice and research. It will be of interest to nurses and nursing leaders who wish to develop supervision programs.

What is already known about this topic?

- Compassion fatigue, emotional labour and moral distress contribute to nurse burnout.

- Group Clinical Supervision can help mitigate stress, enhance learning and support interpersonal aspects of nursing care.
- The supervisory alliance is an important factor in effective clinical supervision whilst group cohesion is an important factor in the effectiveness of group work.

What this paper adds:

- Reflective Practice Groups (RPG) are defined as a form of Group Clinical Supervision that utilise social support as a resource.

- RPG facilitation principles are aligned with social psychology constructs of group identity, task interdependence and homogeneity.

- Alliance with the facilitator and cohesion within the group, enhanced by voluntary participation and facilitation techniques, allow group members to access restorative and formative benefits whilst prompting self-evaluation against the group ideal nursing prototype.

Keywords: Group clinical supervision, reflective practice, group cohesion, nursing, social psychology, stress

\section{INTRODUCTION}

Many nurses choose to enter the profession from a desire to provide care to others and for some it is viewed as a vocation. ${ }^{1,2}$ Within contemporary healthcare environments, this social identity prototype of the holistic, caring nurse can be difficult to realise, especially in the face of time constraints, administrative demands and mounting task requirements. ${ }^{1,3} \mathrm{~A}$ growing focus on the role of technology and the biomedical model may further limit opportunities for contact with patients. ${ }^{4}$ It is unsurprising that work-related stress for nurses can be closely related to difficulties in realising their caring role.

Compassion fatigue, ${ }^{5}$ emotional labour, ${ }^{6}$ and moral distress have been found to contribute to nurse burnout. ${ }^{7,8}$ Various interventions have been developed to try and reduce workplace stress for nurses. Some, such as Group Clinical Supervision (GCS), draw on social support as a resource, ${ }^{9}$ however most research into GCS has focused on the impact of the intervention rather than group dynamics and processes.

In the context of the 2019 joint position statement by Australia's peak nursing and midwifery bodies advocating clinical supervision for nurses, ${ }^{10}$ this paper explores group process mechanisms in a longstanding reflective practice group (RPG), a form of GCS for nurses. ${ }^{11}$ We examine how these mechanisms relate to existing theoretical frameworks and how they inter-relate with the role of the facilitator. There are a number of precedents for Consultation Liaison (CL) mental health clinicians providing supervision to nurses and this paper explores one such relationship, ${ }^{11-13}$ supporting the idea that the CL nurse may be particularly well positioned to facilitate RPG for intensive care nurses. ${ }^{14}$ On the other hand, RPG's could occur in a range of clinical settings, and be facilitated by appropriately trained individuals from a range of other nursing backgrounds and other disciplines. ${ }^{12,28}$ Consequently, the underpinning principles, considerations and strategies outlined in this study are proposed to have validity and utility for RPG/GCS facilitation in general.

\section{BACKGROUND}

The literature on clinical supervision for nurses contains a number of ambiguities. ${ }^{15}$ Interventions such as support groups, reflective practice groups and other forms of GCS can use similar formats, and labels are used interchangeably. ${ }^{16,17}$ In this climate, one of the most enduring frameworks for nursing supervision is the Supervision Alliance Model which proposes three main functions of clinical supervision: formative, normative and restorative.$^{18}$ Emphasis can be given to each of these three functions depending on group needs, ${ }^{12,19}$ with recent research indicating that nurses often value the restorative aspects of GCS above the normative and formative. ${ }^{12,20}$ Butterworth and colleagues demonstrated the effectiveness of stress reduction for nurses attending GCS in a randomised controlled trial in the United Kingdom and other recent empirical research has also highlighted restorative benefits. ${ }^{12,21,22}$ Despite these studies, research findings are not consistent and some even indicate that GCS can have detrimental effects such as personal and professional 
estrangement. 15,23,24 Studies also identify that the benefits of GCS might be undermined when a lack of organisational support results in reduced attendance or when participant values are incongruent with those of the health system. . $5,26^{2}$

The literature describes key factors for effective GCS as consistency in approach, dedicated timing, sharing of emotions and constructive feedback from the supervisor. ${ }^{27}$ These factors are promoted and enhanced by the provision of a safe environment and by effective supervision skills. ${ }^{28,29}$ Some models draw on psychoanalytical frameworks or discuss GCS in terms of Freudian transference. ${ }^{16,30}$ Others utilise Yalom's group psychotherapy model that identifies 11 therapeutic factors: instillation of hope, universality, imparting information, altruism, the corrective recapitulation of the primary family group, the development of socialising techniques, imitative behaviour, interpersonal behaviour, interpersonal learning, group cohesiveness, catharsis, and existential factors. ${ }^{31,32}$ These factors are interrelated, with some being more salient for certain groups than others.

Group cohesiveness is a dominant focus of clinical and research literature with Yalom defining it as an essential but more complex form of the therapeutic alliance essential for individual therapy. ${ }^{16,31,33,34}$ Literature on nursing GCS also identifies trust, cohesion and a safe environment as important factors, ${ }^{14,28,29}$ however, there have been challenges defining the factors that determine group cohesion and therefore, there is inconsistency in its measurement. 35 Hornsey, Dwyer, and Oei attempt to articulate group cohesion using a social psychology lens and offer three explanatory constructs: group identification, homogeneity, and task interdependence. ${ }^{33}$

Group identity provides a schema for the appropriate emotions and behaviours of group members in context. ${ }^{36}$ In group therapy research, group identity has been linked to increased trust among members..$^{37,38}$ Although strong identification can lead to conformity and lack of dissent in group interactions, 33 Haddock suggests that for nurses, supportive reflection in a group setting encourages disclosure of emotions and behaviours that are inconsistent with nursing social identity. ${ }^{39}$ While this is a challenging experience, if appropriately facilitated in a safe environment, it can lead to increased self-awareness, tolerance, clinical insights and emotional working through. ${ }^{11}$

Homogeneity is the perceived similarity of group members and is proposed to assist the formation of group identity. ${ }^{33}$ In group therapy settings, homogeneity of group members is associated with increased levels of empathy and perspective taking. ${ }^{40}$ Task interdependence is defined as how much an individual needs other people to meet self-interests. ${ }^{33}$ In a group therapy setting, participants help others while also meeting their own needs, providing a sense of social competence, self-esteem, mutual interest and caring. ${ }^{16,41}$
Helping others is consistent with the key value of caring embedded in the social identity of nursing and can help promote self-disclosure as a form of altruistic but mutually rewarding experience, enabling the group and its individual members to move towards the common goals of GCS. ${ }^{18,42,43}$

There is a growing appreciation of social identity theory in contemporary nursing literature and a corresponding understanding of the importance of professional identity, 44,45 so a social identity framework for cohesion in nursing GCS seems particularly relevant. 33

\section{METHODS}

\section{DESIGN}

Data were generated through three semi-structured focus groups conducted in mid-2018 with a cohort of intensive care nurses. Data collection preceded an extensive literature review to minimise the risk of preconceived hypotheses and reduce the potential for bias.

Thematic analysis methods were consistent with Braun and Clarke with a focus on process during analysis, helping to identify repeated patterns of meaning as well as relationships between RPG interactions and outcomes..$^{46,47}$

\section{PARTICIPANTS}

Participants were recruited from 120 nursing staff working in the intensive care unit (ICU) of an Australian regional tertiary hospital. Participation was voluntary and based on convenience. Focus groups were held during the allocated time and usual location of the RPG to replicate the safe space. The criterion for inclusion in the focus groups was previous attendance at the RPG. Participants $(\mathrm{N}=22$, female $=19$, male $=3$ ) were aged 23 to $60+$ years $(m=36)$ and had two to 32 years of nursing experience $(m=12)$, on average attending the RPG for five years. Three focus groups were held, with eight, 10 and four participants, respectively.

\section{DATA COLLECTION}

The focus group convenor was a female psychology honours student who had no previous association with focus group participants but who did have prior experience in health and human services (Author 1). Conscious that emerging themes might reflect the interaction between researcher and participants, flexibility in the questioning aimed to encourage participant driven discussion. This semistructured approach allowed analysis to evolve from a series of initial questions that informed subsequent questions. 47 Questioning began by asking participants to describe to a new colleague how the RPG functions, secondly whether participants would encourage the colleague to attend the RPG and why, third how the safe space in the RPG was created, fourth how issues of conflict were resolved in the RPG and finally to explain the role of the facilitator. 


\section{DATA ANALYSIS}

Consistent with Braun and Clarke's thematic analysis approach, six steps of coding took place; familiarisation with the data generated from the focus groups, generating initial codes, searching for themes among codes, reviewing themes, defining and naming themes, and producing the final report, including retrospective comparison to the literature. ${ }^{46}$ Theoretical saturation was achieved after the second focus group, with the third group used to test and confirm findings.

\section{FINDINGS}

The themes that emerged had a hierarchical relationship. Shared professional group identity and voluntary participation were prerequisites for a safe space, which was then maintained throughout sessions by effective facilitation skills. These were called 'Enabling Factors'. The establishment of a safe space enabled participants to self-disclose, leading to an increased sense of universality and empathy, providing respite from emotional labour. These have been termed 'Outcome Factors'. Results are illustrated as a flow chart in Figure 1 and expanded on in the section below, including direct quotes from the focus groups.

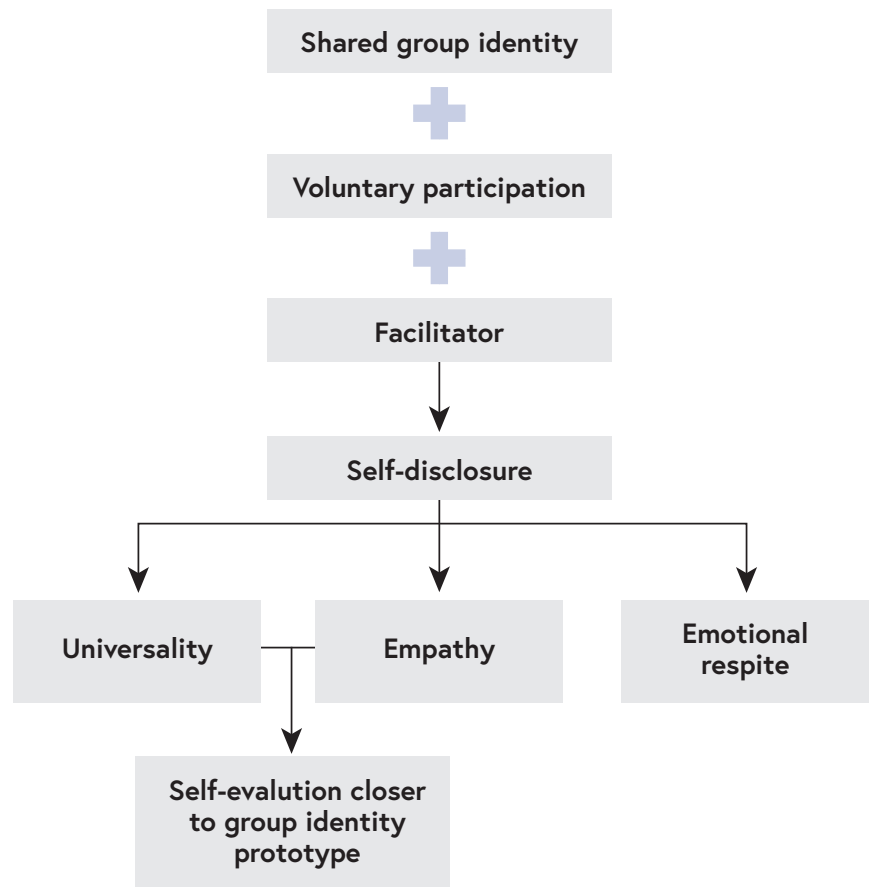

FIGURE 1: FLOWCHART SHOWING HOW ENABLING FACTORS, THROUGH SELF-DISCLOSURE, RESULT IN OUTCOMES AND CRITICAL REFLECTION AGAINST THE IDEAL NURSING PROTOTYPE

\section{ENABLING FACTORS}

\section{Homogeneity/shared group identity.}

Although the RPG met fortnightly, attendance varied dependent on rosters. This means it was not a closed group, so professional homogeneity provided an important uniting factor in the creation of a safe space. That is, the group was comprised of ICU nurses with similar clinical experiences. The number of group members was not important to group outcomes as the following speech sample suggests: “...not always the same people... and there are always different numbers, sometimes five and sometimes 17. So you can't call yourself a group... a group would be the same people all the time, whereas we are people that come to reflective practice." (Nurse, 6o+)

The decision of who attended was a deliberate and evolving process for the group.

"We actually talked about having [nurse unit managers] ... we weren't happy with that... [they] are administrative."

(Nurse, 35)

\section{Voluntary Participation}

One emergent theme that was seen to contribute to homogeneity, appreciation of diversity and mutual respect, was the importance of voluntary participation.

“...You want people to come along to the group because they want to be there, because if they don't want to be there, my concern is that they... might not get anything out of it, or they may not contribute to the group, and may not say anything anyway, and that's fine, but you certainly don't want to force people into this kind of environment, where certain things might be discussed that they don't want to take part in" (Nurse, 47).

"We all know why we are here, and we are all different but respect each other" (Nurse, 6o+).

At times, the clinical material raised during the RPG might be challenging and the focus groups identified that participants needed to be willing to process difficult topics and emotions. ${ }^{23}$

“... Something that is said might be quite confronting and you really have to choose to be here" (Nurse, 60+).

RPG homogeneity, enhanced through voluntary attendance, allowed the establishment of a set of group norms that further helped define the group's identity.

"[RPG] is more of a process than a group [but] it is the group setting, and you need to follow the rules"(Nurse, 32). 


\section{Facilitator Effect}

The facilitator was a Consultation Liaison Mental Health Nurse working within the agency. The facilitator assisted the group to explicate group rules and norms in the form of a 'contract' which was reiterated during sessions and contributed to the maintenance of group identity.

"There is definitely a clear set of expectations as well, [the facilitator] manages the room, pulling people up if they were maybe crossing a line and starting to get a bit [angry]...no one was going to chew your head off, because [the facilitator] was there. You felt like you could talk and that it was OK”(Nurse, 44).

One key RPG rule was confidentiality, which was viewed as essential to establishing trust. Furthermore, the facilitator's ability to represent and enact these principles and processes within the RPG was seen to enhance the sense of safety within the group. The facilitator was viewed as "someone very relatable, someone very trustworthy, you cannot have just anyone" (Nurse, 35).

"... It's like this activity that you do with [ the facilitator]. [The facilitator] makes us all really safe" (Nurse, 26).

Focus group participants identified three further factors contributing to facilitator credibility: relationship to the group through their professional role, genuine commitment to the group, facilitation style and technique. A preexisting clinical relationship appeared to enhance group identification with the facilitator and contribute to facilitator credibility.

"[The facilitator] actually comes to ICU ... and understands the environment we work in.... He is clinical, he walks the talk."

(Nurse, 49)

"He's one of us, but not too close to home. And I think that works, because we are not seeing [ the facilitator] every day, he's not too close" (Nurse, 6o+)

"We respect [the facilitator] because we see [the facilitator] in action. He is calm and so intuitive... [the facilitator] just has this calm about him that can put you at ease."(Nurse, 6o+)

Participants believed the facilitator genuinely cared about the welfare of nurses and really wanted to be there, complementing the voluntary nature of their participation.

"... You get the feeling that he wants to be here, and he understands the importance and value of it....that he is not just here because it's his job. He does it because he understands people, particularly in this area". (Nurse, 37)

The facilitator helped the group remain focused so issues could be examined from a range of perspectives.

"There is a lot of reading between the lines, he will come back and revisit and explore further and tease it out a bit."... "[ the facilitator] tries to... keep on that topic so that you actually get something out of it”(Nurse, 47).
However the facilitator was seen to enlist the group to explore the issues raised:

"to throw it back to the group to find the answer... [the

facilitator] doesn't need to have the answer" (Nurse, 35).

The facilitator was seen to manage the process when emotions or conflict arose within the group:

"So [ the facilitator] kind of just worked through the conflict and brought it back down a level and I see [the facilitator] practice the things that he teaches us to do with our patients; like mirroring, bringing down the volume, giving people a minute to breathe before coming back to them. [The facilitator] is good at using the room, to let that person have a break from their emotions for a minute." (Nurse, 26)

The facilitator also reframed participant statements, to increase understanding, validate nurse's experience and promote critical reflection whilst maintaining a supportive space.

"If you have an opinion and you don't quite have the words to say it well, and someone gets defensive, [the facilitator] will say, 'well, did you mean it like this'... you don't have to be concerned about upsetting someone just because you can't communicate well." (Nurse, 33)

"You might deal with a really hairy situation or a really hard family or something like that, and you'll talk about it in here and [ the facilitator] will sort of give you a new perspective. From what you've said to me this is what it sounds like what was happening. This is why they may have reacted this way". (Nurse, 44)

The less formal, more facilitative style of reflecting in the RPG was valued as being different to that practiced in academic settings.

“... when you do it at [university], it is very regimented, it's like here is the [formal] reflective cycle. Use it with a bunch of references to tell me how you feel, it is not necessarily an intuitive way to reflect on your practice, or I didn't find anyway... These reflective groups are a little more free form ... you can bounce a few ideas off each other. It's just a bit more intuitive, and you've actually got some real patients to do it on.... it's you know real life that goes on in here."(Nurse, 26)

\section{Self-Disclosure}

"[RPG] is an opportunity to talk about actual patient cases and in our job we really don't have the opportunity to do that. We can't go home and tell the husband about it because of patient confidentiality, so this is a chance to openly talk about things from work. It is a safe space" (Nurse, 24). 
Participants felt they could express honest emotions without judgement.

"This is one of the unique spaces where you can be more vulnerable, and not be so worried about being as confident in the situation that you'd like to be... it's ok for people to see you that way". (Nurse, 32)

Self-disclosure by one participant increased the confidence of others to express emotion, fostering mutuality.

"If someone is willing to take the risk and expose themselves, then I think ... that is exactly what I felt. That is when the respect that I have for someone increases. And that may be the breaking point for someone, but that is actually $\mathrm{OK}$, as it means I am more willing to take the risk to expose myself. When I feel personally affected, then this is a positive outcome from someone exposing themselves." (Nurse, 30 )

\section{OUTCOME FACTORS}

\section{Universality}

By sharing emotions and issues, group members gained a sense of universality, that is, they were not alone in their experiences or responses.

"The best thing, whether people realise it or not is to realise that we are all going through the same thing”. (Nurse, 47)

"When you don't know if what you are feeling is normal or not. I remember one time when [a colleague] had been through the exact same situation, and felt the exact same way, and it was really comforting to know that this was completely normal." (Nurse, 42)

"Often a colleague brings things up anyway, and you realise you've been holding on, and you've forgotten about it and all of a sudden in that space you just let go and find camaraderie and realise that you are not the only one". (Nurse, 26)

\section{Empathy}

By sharing experiences of difficult patients, families and colleagues, the group and the facilitator could provide insight into what patients and families might be experiencing, potentially building empathy with patients, families and colleagues.

"I think there is a greater understanding of personalities and situations and how to handle it and empathy and support subconsciously...just hearing what others are going through, and the different things about colleagues is helpful. Sometimes coming to reflective practice can make you realise what someone is going through. It makes you realise that you work with actual people. It can help to start a conversation with them, especially as I am not here often enough to know people well". (Nurse, 30)

\section{Emotional respite or unburdening}

A product of sharing difficult experiences and emotions was a sense of release; that issues shared were no longer as much of a burden.

"If someone had just gone through a really [bad] shift and there has been something bad, then they need to just blah"(Nurse, 49)

"It's about releasing those feelings or subjects that you may not have felt comfortable to in a different space”, (Nurse, 23)

Different group outcomes can depend on the participants in the RPG on the day and the needs of the group at the time

"There are two different types of blowing off steam, there is one that's just catharsis, and the other that is seeing a solution to whatever issue you've got, and so there are two different types of groups, those wanting to let off steam and not really caring about trying to fix things or actually seeking feedback, and those wanting to work through whatever issue you've got" (Nurse, 47)

\section{DISCUSSION}

Two key structures have emerged from the focus groups: enabling factors (group identity, voluntary participation, facilitation, self-disclosure) and outcome factors (universality, empathy and respite from emotional labour). In turn we infer that through this process, the group develops an ideal nurse prototype that is consistent with their lived experience of the nursing role. The enabling factors align with social psychology constructs of group identity, homogeneity and task interdependence whilst outcome factors are proposed to correspond with the Supervision Alliance Model's restorative, formative and normative functions of supervision. . $^{1833,35}$ Respite from emotional labour is a restorative benefit. The development of empathy can be seen as a formative process with both emotional and cognitive elements linked to the development of awareness and insight. Universality is considered both normative and formative; allowing nurses involved in RPG to evaluate their actions and reactions, then modify them. Whilst this interpretation of normative does not necessarily address managerial perspectives and benchmarks, it does relate to professional quality assurance and best practice in nursing care.

Developing the perception of homogeneity within the RPG was a deliberate process that capitalised on existing social frameworks. Initially this occurred through acknowledgement of the clinical and workplace subculture, as nursing identity is particularly salient at work-unit level,45 then enhanced by voluntary participation. The resulting sense of group ownership and empowerment both required and engendered reciprocity and mutual respect that was significant in enabling self-disclosure and unburdening. ${ }^{28}$ Participants shared common issues and experiences, which 
were explicated and explored in the group to enhance shared understanding. Although Hornsey and colleagues suggest that homogeneity can lead to conformity and reduce therapeutic effectiveness, 35 in this occupational setting homogeneity was seen to allow self-evaluation and move participants closer to prototypical nursing ideals. Professional homogeneity provided the foundation upon which group rules (e.g. confidentiality and respect) were established. Rather than being a set group of people, the RPG was able to develop its own identity based on a negotiated set of rules, processes and norms..$^{48}$ The facilitator played a key role in this process; ${ }^{24,28}$ reiterating these rules and modelling norms, as well as periodically reviewing these with the group to allow its identity to evolve. This assisted in creating a safe container within which the group could process work related stresses and challenging situations. ${ }^{11,12}$

Voluntary participation was seen to enhance task interdependence. Group and individual objectives were aligned within the RPG and the group provided the permission and mechanisms for participants to emotionally unburden, build empathy for others, achieve a sense of universality and thereby feel 'normal'; 48,49 something they believed they could not achieve alone. At times this could be a difficult process however, so nurses made an informed choice to attend. The resulting self-disclosure in group was seen to enhance both self-comparison and self-compassion. Universality has been identified as a key theme in previous research on GCS for nurses. ${ }^{27}$ Confirmation of nursing attitudes and actions and the normalising of experiences in a peer context can provide a catalyst for constructive self-evaluation and movement towards the group identity prototype of the professional, caring nurse. ${ }^{18,50}$

The relationship between the group and the facilitator was based on professional identification and a perception of credibility; enhanced by facilitation style and technique, ${ }^{24,28}$ allowing for social modelling of the desired nursing prototype. The facilitator demonstrated interpersonal skills associated with this prototype, and was perceived to value nurses, their welfare, and the RPG. Whilst the mental health nurse was well positioned to facilitate RPG for ICU nurses, facilitators may come from a range of disciplines and clinical backgrounds. ${ }^{12,13}$

The cohesive, well performing group can have a homeostatic function; helping to contain and process the emotional material brought into the reflective space. ${ }^{11,48,51}$ The relationship between facilitator and group, plus the cohesion developed within the group, comprises a complex and important alliance as important in supervision as it is in therapy. ${ }^{31,34}$

\section{LIMITATIONS}

Given the exploratory nature of this study we chose a convenience sample, one not necessarily representative of all nursing clinical or supervision environments. An ICU is not representative of all nursing environments, however, the study involved nurses from a range of ages, experience, and duration of RPG attendance.

This study represents a moment in time for a particular group. Given that there are stages of group development, ${ }^{51}$ it must be acknowledged that this RPG and its processes have evolved and will continue to evolve. This is particularly pertinent as the longevity and success of the group is noted to be inter-related with the continuity of the facilitator.

This study drew exclusively on the perspectives of the RPG participants. Future research could explore the social psychology of group processes from the facilitator's perspective, building on the descriptive work of Miller and Scanlon. ${ }^{16,52}$

\section{CONCLUSION}

This study supports key facilitation principles outlined in the RPG model, ${ }^{11,28}$ framing them within a social psychology construct for cohesion in groups. 33

The study elucidates factors that contribute to facilitator credibility and effectiveness and raises awareness of processes that can enhance the outcomes of RPG. The longevity and success of the RPG in this study involves the relationship between facilitator and group, and the cohesion developed within the group. This alliance, enhanced by voluntary participation, enables the formation of a group identity based on homogeneity, universality and interdependence. Facilitation style and techniques prompt self-evaluation against the group ideal nursing prototype, and create a safe, supportive, but sometimes challenging space for members to self-disclose and access restorative, formative and normative benefits. ${ }^{18}$

Social psychology theory can assist in the development and evaluation of RPG/GCS frameworks and guide research. Whilst this study focuses on intra-group processes, a future phenomenological study might explore intra-personal processes. 


\section{REFERENCES}

1. Hoeve $Y$, Jansen G, Roodbol P. The nursing profession: public image, self-concept and professional identity: a discussion paper. J Adv Nurs. 2014; 70(2), 295-309. Available from: https://doi.org/10.1111/jan.12177

2. Eley D, Eley R, Bertello M, Rogers-Clark C. Why did I become a nurse? Personality traits and reasons for entering nursing J Adv Nurs. 2012; 68(7),1546-55. Available from: https://doi.org/10.1111/j.1365-2648.2012.05955.x

3. Harvey C, Thompson S, Pearson M, Willis E, Toffoli L. Missed nursing care as an 'art form': the contradictions of nurses as carers. Nurs Inq. 2017; 24(3). Available from: https://doi.org/10.1111/nin.12180

4. Jakimowicz S, Perry L. A concept analysis of patient-centred nursing in the intensive care unit. J Adv Nurs. 2015; 71(7), 1499-517. Available from: https://doi.org/10.1111/jan.12644

5. Hegney D, Craigie M, Hemsworth D, Osseiran-Moisson R, Aoun $\mathrm{S}$, Francis $\mathrm{K}$, et al. Compassion satisfaction, compassion fatigue, anxiety, depression and stress in registered nurses in Australia: study 1 results. J Nurs Manage. 2014; 22(4), 506-18. Available from: https://doi.org/10.1111/jonm.12160

6. Gray B, Smith P. Emotional labour and the clinical settings of nursing care: the perspectives of nurses in East London. Nurse Educ Prac. 2009; 9(4), 253-61. Available from: https://doi.org/10.1016/j.nepr.2008.08.009

7. Mealer M, Moss M. Moral distress in ICU nurses. Intens care med. 2016; 42(10), 1615-7. Available from: https://doi.org/10.1007/s00134-016-4441-1

8. Khamisa N, Peltzer K, Oldenburg B. Burnout in relation to specific contributing factors and health outcomes among nurses: a systematic review. Int J Environ Res Public Health 2013; 10(6), 2214-40. Available from: https://doi.org/10.3390/ ijerph10062214

9. Rodrigues N, Cohen L, McQuarrie S, Reed-Knight B. Burnout in nurses working with youth with chronic pain: a pilot intervention. J Pediatr Psychol. 2017; 43(4), 382-91. Available from: https://doi.org/10.1093/jpepsy/jsx132

10. Australian College of Mental Health Nurses, Australian College of Midwives, and Australian College of Nursing position statement: clinical supervision for nurses \& midwives. Australian College of Mental Health Nurses, Australian College of Midwives, and Australian College of Nursing. 2019. [cited 2021 June 28]. Available from: https://www.midwives.org. au/sites/default/files/uploaded-content/field f content file/20190408 clinicalsupervision final.pdf

11. Dawber $\mathrm{C}$. Reflective practice groups for nurses: a consultation liaison psychiatry nursing initiative: part 1-the model. Int J Ment Health Nurs, 2013; 22(2), 135-44. Available from: https://doi.org/10.1111/j.1447-0349.2012.00839.x

12. Koivu A. Clinical Supervision and well-being at work, a four-year follow-up study on female hospital nurses. University of Eastern Finland, Faculty of Health Sciences. Publications of the University of Eastern Finland: Dissertations in Health Sciences 175; 2013. Available from: http://urn.fi/URN:ISBN:978-952-61-1148-3

13. Watson DE. Psychiatric liaison services to the critical care nursing staff. Critical Care Update! 1977; 4 (5)

14. Dawber C, O'Brien T. A longitudinal, comparative evaluation of reflective practice groups for nurses working in intensive care and oncology. J Nurs \& Care. 2013; 3: 138. Available from: https://doi.org/10.4172/2167-1168.1000138
15. White E. Measuring clinical supervision; how beneficial is yours and how do you know? J Adv Nurs. 2018; 74: 1437-39. Available from: https://doi.org/10.1111/jan.13529

16. Scanlon C. Working with disappointment in difficult places: group-analytic perspectives on Reflective Practice and Team Development (RPTD) in organisations. Contexts. 2017; 75: 23-36.

17. Freshwater D. Reflective practice and clinical supervision: two sides of the same coin. In: Bishop $V$, editor. Clinical supervision in practice: Some questions, answers and guidelines for professionals in health and social care. 2nd Ed. Basingstoke, England: Macmillan Press; 2007.

18. Proctor B. Supervision: a co-operative exercise in accountability. In: Marken M, Payne M, editors. Enabling and ensuring: supervision in practice. National Bureau and Council for Education and Training in Youth and Community Work. Leicester. 1991; 21-3

19. Pollock A, Campbell P, Deery R, Fleming M, Rankin J, Sloan $G$, et al. A systematic review of evidence relating to clinical supervision for nurses, midwives, and allied health professionals. J Adv Nurs. 2017; 73(8): 1825-37. Available from: https://doi.org/10.1111/jan.13253

20. Sheppard F, Stacey G, Aubeeluck A. The importance, impact and influence of group clinical supervision for graduate entry nursing students. Nurse Educ Prac. 2018; 28: 296-301. Available from: https://doi.org/10.1016/j.nepr.2017.11.015

21. Butterworth T, Carson J, Jeacock J, White E, Clements A. Stress, coping, burnout and job satisfaction in British nurses: findings from the clinical supervision evaluation project. Stress Med. 1999; 15(1); 27-33. Available from: https://doi.org/10.1002/(SICI)1099-1700(199901)15:1<27:.AIDSMI782>3.0.CO;2-U

22. Nordbøe C, Enmarker I. The benefits of person-centred clinical supervision in municipal healthcare-employees' experiences. Open J Nurs. 2017; 7: 548-60. Available from: https://doi:10.4236/ojn.2017.75042

23. Jones A. Clinical supervision: what do we know and what do we need to know? A review and commentary. J Nurs Manag. 2006; 14(8): 577-85. Available from: https://doi.org/10.1111/j.1365-2934.2006.00716.x.

24. Platzer $H$, Blake D, Ashford D. Barriers to learning from reflection: a study of the use of group work with postregistration nurses. J Adv Nurs. 2000; 31(5): 1000-8. Available from: https://doi.org/10.1046/j.1365-2648.2000.01396.x

25. Buus N, Angel S, Traynor M, Gonge H. Psychiatric nursing staff members' reflections on participating in group based clinical supervision: a semi-structured interview study. Int J Ment Health Nurs. 2011; 20(2): 95-101. Available from: https://doi.org/10.1111/j.1447-0349.2010.00709.x

26. Deery, R. An action-research study exploring midwives' support needs and the affect of group clinical supervision. Midwifery. 2005; 21(2): 161-76. Available from: https://doi.org/10.1016/j. midw.2004.10.006

27. Cross W, Moore A, Ockerby S. Clinical supervision of general nurses in a busy medical ward of a teaching hospital. Contemp Nurse. 2010; 35(2): 245-53. Available from: https://doi. org/10.5172/conu.2010.35.2.245

28. Platzer $\mathrm{H}$, Blake D, Ashford D. An evaluation of process and outcomes from learning through reflective practice groups on a post-registration nursing course. J Adv Nurs. 2008; 31(3): 689-95. Available from: https://doi.org/10.1046/j.1365$\underline{2648.2000 .01337 . x}$ 
29. Carver N, Clibbens N, Ashmore R, Sheldon J. Mental health pre-registration nursing students' experiences of group clinical supervision: A UK longitudinal qualitative study. Nurse Educ Prac. 2014; 14(2): 123-9. Available from: https://doi.org/10.1016/j.nepr.2013.08.018

30. Regan P. Reflective insights on group clinical supervision; understanding transference in the nursing context. Reflective Prac. 2012; 13(5): 679-91. Available from: https://doi.org/10.1080/14623943.2012.697880

31. Yalom I. The theory and practice of group psychotherapy. 4th ed. New York: Basic Books; 1995.

32. Yalom I, Leszcz M. The theory and practice of group psychotherapy. 5th ed. New York: Basic Books; 2005.

33. Hornsey M, Dwyer L, Oei T. Beyond cohesiveness: Reconceptualizing the link between group processes and outcomes in group psychotherapy. Small Group Res. 2007; 38(5): 567-92. Available from: https://doi.org/10.1177/1046496407304336

34. Lambert M J, Barley, D E. Research summary on the therapeutic relationship and psychotherapy outcome. Psychother Theor Res Prac Train. 2001; 38(4):, 357-61. https://doi.org/10.1037/0033$\underline{3204.38 .4 .357}$

35. Hornsey M, Dwyer L, Oei T, Dingle G. Group processes and outcomes in group psychotherapy: is it time to let go of "cohesiveness"? Int J Group Psychother. 2009; 59(2): 267-78. Available from: https://doi.org/10.1521/ijgp.2009.59.2.267

36. Tajfel $H$, Turner J. The social identity theory of intergroup behaviour. In: Worchel S, Austin WG, editors. Psychology of intergroup relations. Chicago: Nelson-Hall; 1986; 7-24. Available from: https://doi.org/10.4324/9780203505984-16

37. Tanis M, Postmes T. A social identity approach to trust: interpersonal perception, group membership and trusting behaviour. Eur J Soc Psychol. 2005; 35(3): 413-24. Available from: https://doi.org/10.1002/ejsp.256

38. Voci A. The link between identification and in-group favouritism: effects of threat to social identity and trust-related emotions. Br J Soc Psychol. 2006; 45(2): 265-84. Available from: https://doi.org/10.1348/014466605X52245

39. Haddock J. Reflection in groups: contextual and theoretical considerations within nurse education and practice. Nurse Educ Today. 1997; 17(5): 381-85. Available from: https://doi. org/10.1016/S0260-6917(97)80099-8

40. Cialdini R, Brown S, Lewis B, Luce C, Neuberg S. Reinterpreting the empathy-altruism relationship: when one into one equals oneness. J Pers Soc Psychol. 1997; 73(3): 481. Available from: https://doi.org/10.1037/0022-3514.73.3.481

41. Comeau D, Griffith R. Structural interdependence, personality, and organizational citizenship behaviour: an examination of person-environment interaction. Pers Rev. 2005; 34(3): 310-30 Available from: https://doi.org/10.1108/00483480510591453

42. Dahlke S, Stahlke Wall S. Does the emphasis on caring within nursing contribute to nurses' silence about practice issues? Nurs Philos. 2017; 18(3): e12150. Available from: https://doi. org/10.1111/nup.12150

43. Fan E, Gruenfeld D. When needs outweigh desires: the effects of resource interdependence and reward interdependence on group problem solving. Basic Appl Soc Psych. 1998; 20(1): 45-56. Available from: https://doi.org/10.1207/ s15324834basp2001 5
44. Rasmussen P, Henderson A, Andrew N, Conroy T. Factors influencing registered nurses' perceptions of their professional identity: an integrative literature review. J Contin Educ Nurs. 2018; 49(5): 225-32. Available from: https://doi. org/10.3928/00220124-20180417-08

45. Willetts G., Clarke D. Constructing nurses' professional identity through social identity theory. Int J Nurs Pract. 2014; 20(2): 164-9. Available from: https://doi.org/10.1111/ijn.12108

46. Braun V, Clarke V. Using thematic analysis in psychology. Qual Res Psychol. 2006; 3(2): 77-101. Available from: https://doi.org/10.1191/1478088706qp063oa

47. Charmaz K. Constructing grounded theory: a practical guide through qualitative analysis (Introducing qualitative methods). London: Sage; 2006

48. Altfeld D. An experiential group model for psychotherapy supervision. Int J Group Psychother. 1999; 49: 237-54. Available from: https://doi.org/10.1080/00207284.1999.11491583

49. Gonge H, Buus N. Is it possible to strengthen psychiatric nursing staff's clinical supervision? RCT of a meta-supervision intervention. J Adv Nurs. 2015; 71(4): 909-21. Available from: https://doi.org/10.1111/jan.12569

50. Severinsson E, Hallberg I. Clinical supervisors' views of their leadership role in the clinical supervision process within nursing care. J Adv Nurs.1996; 24(1): 151-61. Available from: https://doi.org/10.1046/j.1365-2648.1996.17321.x

51. Tuckman B. Developmental sequence in small groups. Psychol Bull.1965; 63(6): 384-99. Available from: https://doi.org/10.1037/h0022100

52. Miller S. What it's like being the 'holder of the space': a narrative on working with reflective practice in groups. Reflective Prac. 2005; 6(3): 367-77. Available from: https://doi.org/10.1080/14623940500220129 